ARAŞTIRMA / RESEARCH

\title{
Hemiplejik omuzun EMG biofeedback kullanılarak yeniden eğitimi
}

\author{
Reeducation of hemiplegic shoulder by using EMG biofeedback \\ Volkan Deniz ${ }^{1}$, Tunay Sarpel ${ }^{1}$, Savaş Gürsoy² \\ ${ }^{1}$ Cukurova Üniversitesi, Tip Fakültesi, Fiziksel Tip ve Rehabilitasyon Anabilim Dalı, Adana, Turkey \\ ${ }^{2}$ Gaziantep Üniversitesi, Tip Fakültesi, Fiziksel Tip ve Rehabilitasyon Anabilim Dalı, Gaziantep, Turkey
}

\begin{abstract}
Purpose: The aim of our study was to evaluate the effect of EMG biofeedback on hemiplegic shoulder reeducation. Materials and Methods: A total of 30 patients were included in the study. 10 sessions of EMG biofeedback training was given to the upper trapezius muscle on the affected side of the patients during shoulder movements to provide relaxation. Patients were evaluated before and after treatment; the myoelectric activity and tone of the upper trapezius muscle, and only the tone of the deltoideus muscle. Manual Function Test was used to assess functional recovery of the shoulder.

Results: At the end of the treatment, it was seen that there was a decrease in the tone of the upper trapezius muscle and myoelectric activity and an increase in the tone of the deltoideus muscle. According to MFT results, there was a significant improvement in the percentage of shoulder function at the end of treatment. There was no improvement in hand function. In our study, EMG biofeedback training was found to be effective in improving shoulder function in hemiplegic patients.

Conclusion: Preliminary results in this study suggested that in hemiplegic patients, the use of EMG biofeedback with shoulder exercises in the clinic, resulted in favorable outcomes in the treatment.
\end{abstract}

Key words: biofeedback, hemipleji, omuz, tonus, trapezius

\section{GİRİŞ}

Hemipleji, serebrovasküler patolojilere bağlı oluşan ve vücudun karşı yarısında nöromüsküler fonksiyon yetersizliklere neden olan klinik bir tablodur ${ }^{1}$. İnme sonrası görülen en yaygın semptomdur ve akut dönemde hastaların \%80'inde kronik dönemde ise \%40'ından fazlasında görülür ${ }^{2}$. Hemiplejik hastaların

\section{Öz}

Amaç: Çalışmamızın amacı, EMG biofeedback'in hemiplejik omuzun yeniden eğitimi üzerindeki etkisinin değerlendirilmesidir.

Gereç ve Yöntem: Çalışmaya toplam 30 hasta alındı. Hastaların tutulan tarafinda yer alan üst trapezius kasına, omuz hareketleri sırasında, relaksasyon sağlamak amaciyla 10 seans EMG biofeedback eğitimi verildi. Hastaların, tedavi öncesi ve sonrasında; üst trapezius kasının myoelektrik aktivitesi ile tonusu, deltoideus kasının ise sadece tonusu ölçüldü. Omuzdaki fonksiyonel iyileşmeyi değerlendirmek için Manuel Fonksiyon Testi kullanıldı.

Bulgular: Tedavi sonunda üst trapezius kasının tonusunda ve myoelektrik aktivitesinde azalma, deltoideus kasının tonusunda ise artma olduğu görüldü. MFT sonuçlarına göre, tedavi sonunda omuz fonksiyonelliğinde yüzdece anlamlı bir iyileşme olduğu tespit edildi. El fonksiyonlarında ise herhangi bir iyileşme olmadı.

Sonuç: Çalışmamızda EMG biofeedback eğitiminin, hemiplejik hastalarda omuz fonksiyonlarının iyileştirilmesi üzerine etkili olduğu görüldü. Hemiplejik hastalarda, EMG biofeedback ile yapılan omuz egzersizlerinin kliniklerde kullanılmasıyla tedavide olumlu sonuçlar alınabileceği sonucuna varildi.

Anahtar kelimeler: biofeedback, hemipleji, omuz, tonus, trapezius

omuz komplekslerinde görülen problemler; kas zayıflıkları, hipotonus, hipertonus ve normal eklem hareketlerinin kisıtlanmasidir. Bunların yanında koordinasyon problemleri, hareketin planlanmasında veya normal patern içinde uygulanmasında güçlük ve duyusal problemler görülür. Tüm bu problemler 'hemiplejik omuz' sendromuna neden olmaktadır'. Hemiplejik omuz, genellikle üst ektremitenin fonksiyonel iyileşmesinde olumsuz rol oynar ve 
rehabilitasyonun etkilerini sınırlar. Hemiplejik omuzun tedavisinde; konvansiyonel veya gelişmiş fizyoterapi yöntemleri kullanılmaktadır. Hemiplejik hastalarda omuz fonksiyonlarının düzgün olması, giyinme, yemek yeme, kişisel bakım, transfer aktiviteleri ve ambulasyonun(Günlük Yaşam Aktiviteleri) yapılabilmesi açısından önemlidir ${ }^{4}$. M. pectoralis major, $\mathrm{m}$. biceps brachii, ve $\mathrm{m}$. trapeziustaki spastisite, humerus elevasyonunu engelleyeceği için hastanın omuz fonksiyonlarında yetersizliğe ve günlük yaşam aktivitelerinde sınırlanmaya yol açacaktır ${ }^{5}$. Hastalar günlük yaşam aktivitelerini sürdürmek için kompansatuvar stratejiler geliştirirler. Bu stratejiler, yanlış paternlerin gelişmesine neden olur ve iyileşme potansiyellerini bloke eder ${ }^{6}$. Üst ekstremite spastisitesinin kontrol altına alınması veya tedavi edilmesi üst ekstremite rehabilitasyonunda önemli bir yer teşkil eder ${ }^{7}$.

Biofeedback, normal hareket paternlerini fasilite etmek amaciyla 1960 lardan başlayarak günümüze kadar kullanılan bir rehabilitasyon yöntemidir ${ }^{8}$. Elektromyografik (EMG) biofeedback'in muskuloskelatal ve nörolojik rehabilitasyonda etkili olduğu yapılan çalışmalarla gösterilmiştir. EMG biofeedback, zayıf ve denerve kasta fasilitasyon etkisi için kullanılabileceği gibi spastik kasta tonusu azaltmak için de kullanılır'. Bununla birlikte iskemik inme sonrası gelişen hemiplejide, yapılan çalışmalarda EMG biofeedback'in; yürüme kalitesi, omuz eklem hareket açıklığ1 ve kas gücü restorasyonu üzerinde farklı etkileri olduğu bildirilmiștir. Araștırmalarda elde edilen kanıtlar, EMG biofeedback'in hemiplejik hastalarda kullanımı açısından umut vericidir. EMG biofeedback, klinikte en fazla kullanılan ve sonuçları en fazla rapor edilen biofeedback yöntemi olmasına rağmen bu konuyla ilgili daha geniş araştırmaların yapılması gerekmektedir?.

Bu araştırmada, EMG Biofeedback'in hemiplejik üst ekstremite reedükasyonu üzerindeki etkinliğinin değerlendirilmesi ve klinikteki kullanımının yaygınlaştırılması açısından önem taşımaktadır. Literatürde, hemiplejik omuzun EMG biofeedback eğitimi ile tedavi edilmesi konusunda çalışma bulunmamaktadır. Bu açıdan, çalışmanın literatüre katkısının olması amaçlanmıştır.

\section{GEREÇ VE YÖNTEM}

$\mathrm{Bu}$ çalışma, Çukurova Üniversitesi Tıp Fakültesi Balcalı Araştırma ve Uygulama Hastanesi Fiziksel
Tip ve Rehabilitasyon Anabilim Dalında, EMG biofeedback'in hemiplejik omuz reedükasyonu üzerindeki etkisinin değerlendirilmesi amacıyla, kesitsel olarak, 15.02.2017 - 20.05.2017 tarihleri arasında yapıldı. Çalışma protokolü, Çukurova Üniversitesi Tip Fakültesi Girişimsel Olmayan Klinik Araştırmalar Etik Kurulu'nun 13.01.2017 tarihli ve 60 nolu toplantısında değerlendirilmiş olup 50 nolu karar ile çalışmanın Etik Kurul onayı alındı.

Çalışmaya, 42-79 yaş aralığında, nöroloji anabilim dalında hemipleji/hemiparezi tanısı konan ve takibi yapılan, omuz ekleminde aktif hareketi ve semptom süresi $13.80 \pm 7.75$ ay olan 30 hasta dahil edildi. Çalışmaya dahil edilen tüm hastalar, uygulanacak işlemler hakkında ayrıntılı bir şekilde bilgilendirildi. Kişilere, 'Bilgilendirilmiş Gönüllü Olur Formu' okutulup imzaları alındı. Çalışmaya dahil edilen hastaların; adı, soyadı, cinsiyeti, mesleği, semptom süresi, tutulan ekstremiteleri ve dominant ekstremiteleri gibi kişisel bilgileri alındı. Bunlarla birlikte özgeçmiş ve soygeçmişleri incelendi.

\section{Değerlendirme}

Tüm hastaların EMG biofeedback eğitimi öncesinde ve son seansin sonunda, üst ekstremite fonksiyonları değerlendirildi. M. trapezius kas aktivasyonu ile $\mathrm{m}$. trapezius ve $\mathrm{m}$. deltoideus'un tonusu ölçüldü. Manuel Fonksiyon Testi (MFT), hemiplejik hastaların üst ekstremitelerindeki motor fonksiyon defisitlerinin ölçülmesi ve rehabilitasyon sonrası oluşabilecek fonksiyonel iyileşmenin analiz edilebilmesi için geliştirilmiştir ${ }^{10}$. MFT, kol hareketlerini ve manipulatif aktiviteleri ölçen 8 bölüm ve 32 maddeden oluşmaktadır. Hasta bu testten en fazla 32 ve en az 4 puan alabilir.

Kas aktivasyonunun ölçümü için Chattanooga ${ }^{\circledR}$ 2771 model numaralı EMG biofeedback cihazı kullanıldı. Hastadan 10 saniye boyunca aktif olarak kolunu kaldırıp indirmesi istendi. Cihazın 'hedefi belirle' özelliği kullanılarak, 10 saniye boyunca trapeziusun üst bölümünde oluşan motor ünite aksiyon potansiyellerinin ortalama mikrovolt $(\mu \mathrm{V})$ değeri cihaz tarafindan belirlendi.

Dinlenme pozisyonunda kas tonusunun ölçülmesi için MyotonPro ${ }^{\circledR}$ cihazı ( Myoton AS, Talin, Estonya) kullanıldı. MyotonPro yakın zamanda üretilmiş, süperfisyal kasların mekanik özelliklerini ölçen bir cihazdır ${ }^{11}$. Ölçüm yapilırken, hastaların kolları gövde üzerinde destekli bir pozisyon tercih edildi. Ölçüm yapılmadan önce kasların en şişkin 
yerleri kalemle işaretlendi. Cihaz, kasa dik bir pozisyonda yerleştirildi. Ölçüm sırasında cihazın probu deriye $0,18 \mathrm{~N}$ kuvvet ve $15 \mathrm{~ms}$ durasyonla beş defa kısa aralıklarla basınç uygular. Cihazın ekranında kasin; tonus $(\mathrm{Hz}), \quad \operatorname{sertlik}(\mathrm{N} / \mathrm{m}) \quad$ ve elastikiyet $(\%)$ değerleri görülür.

\section{EMG biofeedback uygulamas1}

EMG Biofeedback uygulaması için hastalar, sessiz ve sakin bir odaya alınarak dış ortam ile ilişkileri kesildi. Uygulama yapılmadan önce cilt alkollü pamuk ile iyice silindi. Uygulamada, Stimrodes ${ }^{\circledR} 3.2$ $\mathrm{cm}$ çapında yuvarlak elektrotlar kullanıldı. İki adet aktif elektrot kısa aralıkla (yaklaşı1 $5 \mathrm{~cm}$ ) ve trapeziusun üst bölümünün liflerine paralel olacak şekilde cilt üzerine yerleştirildi. Bir adet referans elektrot aktif elektrotlardan uzak bir alana yerleştirildi. EMG biofeedback uygulaması için Chattonoga ${ }^{\circledR} 2771$ model numaralı cihaz kullanıldı.

Hastalar cihazı rahatlıkla görebilecek konumda ve oturur şekilde pozisyonland. Görsel feedback için cihazın ekranında yer alan kesikli çizgilerden ve işitsel feedback için sinyal sesinden yararlanıldı. Yapılan çalışmada, kasta gevşeme sağlanması amaçlandığ1 için değerlendirmede belirlenen hedef belirli bir yüzdede düşürülerek yeni hedef belirlendi. Hastaların hepsine aktif veya aktif-asistif omuz abduksiyon ve fleksiyon egzersizleri yaptırild. Hastaya, omuz abduksionu ve fleksionu yaparken kesikli çizgilerin hedef çizgiyi geçmemesi gerektiği anlatild1.

Her hastaya iki hafta süresince, haftada beş gün ve günde 15 dakika EMG biofeedback eğitimi uygulandı. Eğitim sirasında her 10 tekrardan sonra 10 saniye dinlenme arası verildi.

\section{İstatistiksel analiz}

Çalışmamızda elde edilen verilerin değerlendirmesi 'SPSS for Windows 20.0' istatistiksel paket program kullanılarak yapıld1. Anlamlılık oran $1 \mathrm{p}<0.05$ olarak kabul edildi. İstatistiksel veriler 'ortalama \pm standart

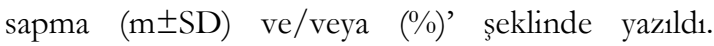
Araştırma sonucunda elde edilen veriler değerlendirilirken, myoelektrik aktivite ve kas tonusunun tedavi öncesi ve sonrası değerlerin analizi için Paired Sample T Test, MFT toplamının ve alt skorlarının değerlendirmesi için Wilcoxon testi kullanıldı. MFT'nin alt skorları için artan hasta oranları (sayıları) kaydedildi.

\section{BULGULAR}

Çalışmaya katılan hastaların; 21(\%70)'i erkek $9(\% 30)$ 'u kadın, tutulan taraflar1 $9(\% 30)$ 'u sağ, 21(\%70)'i sol, dominant taraflar1 27(\%90)'si sağ ve

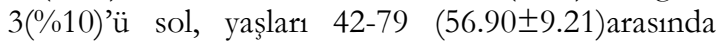
olup semptom süreleri ortalama $13.80 \pm 7.75$ aydır (Tablo 1).

Tablo 1. Hastaların demografik bilgileri

\begin{tabular}{|l|c|c|}
\hline & $\mathbf{n ~ ( \% )}$ & ort \pm SD \\
\hline Cinsiyet $(\mathrm{K} / \mathrm{E})^{*}$ & $9(30) / 21(70)$ & - \\
\hline $\begin{array}{l}\text { Tutulan taraf } \\
\text { (sağ/sol) }\end{array}$ & $9(30) / 21(70)$ & - \\
\hline $\begin{array}{l}\text { Dominant taraf } \\
\text { (sağ/sol) }\end{array}$ & $27(90) / 3(10)$ & - \\
\hline Yaş (yil) & - & $56.90 \pm 9.21$ \\
\hline Semptom süresi (ay) & - & $13.80 \pm 7.75$ \\
\hline
\end{tabular}

*K: Kadın, E: Erkek

Hastaların tedavi öncesinde trapezius kasinın myoelektrik aktivite ortama değeri 192,3 $\pm 61,10$ iken

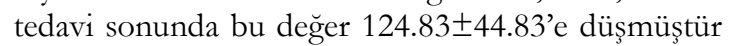
$(\mathrm{p}<0.01)$. Tedavi öncesinde yapilan tonus

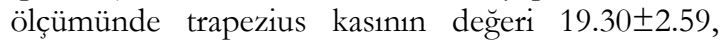
sonunda ise $18.05 \pm 2.26$ olarak bulunmuştur. $(\mathrm{p}=0.01)$. Deltoideus kasinin tonusu tedavi öncesinde 16.83 \pm 1.90 iken, tedavi sonunda

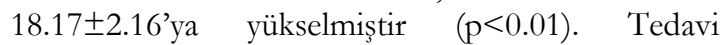
öncesinde, MFT skorlarinın toplaminin ortalama değeri $6.87 \pm 5.29$ dan tedavi sonunda $8.73 \pm 6.04$ 'e yükselmiştir $(\mathrm{p}<0.01)$ (Tablo 2).

Tablo 2.Tonus ve MFT toplam değerleri

\begin{tabular}{|l|c|c|c|}
\hline ort \pm SD & $\begin{array}{c}\text { Tedavi } \\
\text { oncesi }\end{array}$ & $\begin{array}{c}\text { Tedavi } \\
\text { sonras1 }\end{array}$ & $\begin{array}{c}\mathrm{p} \\
\mathbf{d e g} \text { eri }\end{array}$ \\
\hline $\begin{array}{l}\text { MyoelektrikAktivite } \\
(\mathrm{mV})\end{array}$ & $192.3 \pm 61.10$ & $124.83 \pm 44.83$ & $\mathrm{p}<0.01$ \\
\hline $\begin{array}{l}\text { Trapezius Tonusu } \\
(\mathrm{Hz})\end{array}$ & $19.30 \pm 2.59$ & $18.05 \pm 2.26$ & $\mathrm{p}=0.01$ \\
\hline $\begin{array}{l}\text { Deltoideus Tonusu } \\
(\mathrm{Hz})\end{array}$ & $16.83 \pm 1.90$ & $18.17 \pm 2.22$ & $\mathrm{p}<0.01$ \\
\hline $\begin{array}{l}\text { MFT* toplam } \\
\text { skoru }\end{array}$ & $6.87 \pm 5.29$ & $8.73 \pm 6.04$ & $\mathrm{P}<0.01$ \\
\hline *Manuel Fonksiyon Testi
\end{tabular}

MFT'nin alt skorları için; FL testinde tedavi öncesi yapılan ölçümde 1 puan alan $22(\% 73.3)$ hastanın 11 (\%36.7)'i, 2 puan alan 4 (\%13.3) hastanin 1 (\%3.3)'i, 3 puan alan $4(\% 13.3)$ hastanın $4(\% 13.3)$ 'ünün tedavi sonunda puanlarını arttırdıkları, LE testinde; tedavi öncesi yapılan ölçümde 1 puan alan 20 (\%66.7) hastanin 9 (\%30.0)'u, 2 puan alan 7 (\%23.3) hastanın $3(\% 10.0)$ 'ü, 3 puan alan $3(\% 10.0)$ hastanın 2 (\%6.7)'sinin tedavi sonunda puanlarını arttırdıkları, PO testinde; tedavi öncesi yapılan 
ölçümde 1 puan alan $18 \quad(\% 60.0)$ hastanın 7 (\%23.3)'si, 2 puan alan $9(\% 30.0)$ hastanin 2 $(\% 6.7)$ 'si, 3 puan alan $2(\% 6.7)$ hastanin 1 (\%3.3)'inin tedavi sonunda puanlarını arttırdıkları görüldü. 4 puan alan $1(\% 3.3)$ hastanın ise puanının sabit kaldığı, PD testinde; tedavi öncesi yapılan ölçümde 1 puan alan $20 \quad(\% 66.7)$ hastanin 9 (\%30.0)'u, 2 puan alan $8(\% 26.7)$ hastanın 4 (\%13.3)'ü, 3 puan alan $1(\% 3.3)$ hastanın 1 (\%3.3)'inin tedavi sonunda puanlarını arttırdıkları ve 4 puan alan $1(\% 3.3)$ hastanın ise puanının sabit kaldığ1 görüldü. El fonksiyonları ile ilgili olan testlerde ise yüzdece bir artış olmadı.

\section{TARTIŞMA}

Çalışmamız, serebrovasküler olaya bağlı hemipleji/hemiparezi teşhisi konan hastalarda, konvansiyonel fizyoterapi programina ek olarak uygulanan EMG biofeedback eğitiminin omuz reedükasyonu üzerindeki etkisini incelemek üzerine planland. Tedavi sonunda hastaların kas tonusu ve myoelektrik aktivite değerleri ile MFT sonuçlarında tedavi öncesine göre anlamlı sonuçlar elde edildi.

Giggins ve arkadaşları yaptıkları derlemede, EMG biofeedback'in uzun yıllardır hemiplejik hastalarda motor fonksiyon iyileşmesi sağlamak amacıyla uygulanmakta olduğunu fakat etkinliğinin tam olarak kanıtlanmadığını ve bununla ilgili daha kapsamlı çalışmaların yapılması gerektiğini bildirmişlerdir ${ }^{9}$. Hemiplejik hastalara uygulanacak olan EMG biofeedback tedavi protokolü için literatürde görüş birliği bulunmamaktadır. Doğan-Aslan ve arkadaşları hemiplejik hastalarda, spastik el bileği fleksör kaslarını gevşetmek amacıyla 15 seans ve 20 dakikalık bir program uygulamışlardır ${ }^{12}$. Cordo ve arkadaşları EMG biofeedback'in hemiplejik el fonksiyonları üzerindeki etkisini değerlendirmek amaciyla 30 seans ve 30 dakikalık bir program uygulamışlardır ${ }^{13}$. Rayegani ve arkadaşları hemiplejik elde abductor pollicis kasını kuvvetlendirmek amaciyla 10 seans ve 20 dakikalık bir program uygulamışlard $1^{14}$.

Laurençao ve arkadaşları hemiplejik üst ekstremitede EMG biofeedback eğitiminin; spastisite, eklem hareket açılı̆ğı ve üst ekstremite fonksiyonelliği üzerindeki etkisini araştırmak amacıyla 10 seans ve 20 dakikalık bir program uygulamışlardır ${ }^{15}$. Bütün bu programlar göz önüne alınarak çalışmamızda 10 seans ve 15 dakikalık bir program iki hafta boyunca uygulandı. Bu bakımdan literatürdeki çalışmalara göre kısıtlı görülebilir. Bununla birlikte tedavi seanslarının uzun olması kasta yorgunluk oluşturabileceğinden, istenilen gevşeme ve kuvvetlenmenin elde edilebilmesi bakımından olumsuz sonuçların doğabileceğini ve tedavi seans sayısinın fazla olmasinin ise hastanin tedaviye olan ilgisini azaltabileceğini düşündük. Çalışmamızda kontrol grubunun olmaması spontan iyileşmenin bertaraf edilememesi bakımından k1sitllik olarak görülebilir. Bununla birlikte tedavi yapılmayan ve değerlendirmeye alınan el fonksiyonlarında herhangi bir iyileşmenin olmaması spontan iyileşmenin olmadığ1 anlamına gelebilir.

Hemiplejik hastalarda, kas relaksasyonu elde etmek amacıyla, son yıllarda yapılmış iki çalışma bulunmaktadır. Chen ve arkadaşları inme sonrası gelişen hemiplejide, alt ekstremite kaslarına botulinum toksin enjeksiyonunu takiben uygulanan EMG biofeedback eğitiminin spastisite üzerindeki etkisini araştırmışlardır. Bu çalışmada, 36 hastanın yarısına sadece botulinum toksin enjeksiyonu diğer yarısina da enjeksiyonu takiben 10 seans EMG biofeedback eğitimi verilmiş olup değerlendirmede modifiye ashword skalası kullanılmıștır. Tedavi sonunda EMG biofeedback uygulanan grupta modifiye ashword skorlarında kontrol grubuna göre anlamlı bir azalma tespit edildiğini ifade etmişlerdir ${ }^{16}$. Doğan-Aslan ve arkadaşları EMG biofeedback eğitiminin, hemiplejik hastalarda el bileği fleksör kaslarının spastisitesi üzerindeki etkisini araştırmak amacıyla 40 hasta ile 15 seanslık bir çalışma yapmışlardır. Bu çalışmada ashword skalas1, brunnstrom evrelemesi, üst ekstremite fonksiyon testleri, gonyometrik ölçümler ve myoelektrik aktivite ölçümleri veri toplama amacıyla kullanılmışır. Çalışmanın sonucunda, tedavi grubunda kontrol grubuna göre spastisitede ve kasların myoelektrik aktivitelerinde azalma ile el fonksiyonları ve eklem hareket açıklığında artma olduğu bildirilmişlerdir ${ }^{12}$. Çalışmamızda, kas relaksasyonunun tespiti için modifiye ashword skalası yerine myotonmetre kullanıldı. Bunun en önemli nedeni ise, trapezius kasının üst bölümündeki tonus artışının spastisiteden ziyade kasın anormal kullanımı sonucu oluştuğunu düșünmemizdir. EMG biofeedback eğitimi sonucu trapezius kasının anormal kullanımının önlenmesiyle tonusun düzelmesi bu düşüncemizi destekleyen bir kanıttır. Çalışmamızda MFT sonuçlarına göre omuz fonksiyonelliğinde elde edilen iyileşmenin hastaların günlük yaşam aktivitelerine ne oranda fayda sağladığını değerlendirememiş olmamız çalışmanın 
k1s1tlllı̆1 olarak kabul edilebilir. Bununla birlikte hastaların el fonksiyonlarındaki yetersizliğin, omuzdaki kazanımların günlük yaşam aktivitelerine olan olumlu etkisini azaltacağını tahmin etmekteyiz.

Karaduman'a göre; rehabilitasyonun temel hedefi doğal plastisite oluşturmak amaciyla fonksiyonel hareketlerin düzgün yapılmasını sağlamaktır. Kompansatuvar stratejilerin gelişmesi fonksiyonel iyileşmeyi geciktirebilir veya engelleyebilir. Bu bakımdan hemiplejik hastalarda kompansatuvar hareketlerin engellenmesi veya en aza indirgenmesi hedeflenmelidir ${ }^{6}$.

McCrea ve arkadaşları inme sonrası gelişen hemiplejide, kol elevasyonu sirasinda meydana gelen kompansatuvar stratejileri belirlemek amaciyla çalışma yapmışlar. Bu çalışmada, paralitik koldaki elevasyon hareketinde deltoideus kasının zayıflı̆̆ının başka kasların aşırı aktivasyonu ile kompanse edildiğini gözlemlemişler ${ }^{17}$. Trombly ve arkadaşlarının yaptığı çalışmada hemiplejik omuz hareketleri optoelektronik hareket analizi ve EMG ölçümleri ile değerlendirilmiştir. Sonuç olarak, omuz hareketleri esnasinda, hareketten sorumlu ana kasların yeterince aktive olamadığını ve bu kaslar yerine başka kasların aşırı aktive olduğunu söylemektedirler ${ }^{18}$.

Çalışmamızda, omuz eklemi fleksiyonu ve abduksiyonunun, trapezius kasının skapulaya yaptığ1 elevasyonla kompanse edildiğini, yapılan myoelektrik aktivite ölçümüyle tespit ettik. EMG biofeedback eğitimiyle, hastalar omuz hareketleri sirasinda deltoideus kasını kullanarak trapezius kasının üst bölümüyle yapılan kompansasyonu azalttılar. Kompansasyonun azalmasiyla birlikte omuz hareket açıklığının arttığını MFT verilerine bakarak belirledik. Bununla birlikte omuz hareketleri sırasında başka kompansasyonların olabileceğini ve bunun için daha fazla çalışma yapılması gerektiğini düşünmekteyiz.

Glanz'a göre, hemiplejik hastalarda görülen önemli fenomenlerden biri de motor hareketlerin, selektif ve bağımsız kas kontraksiyonları yerine kas sinerjileri veya agonist kasların stereotipik kontraksiyonlarryla yapılmasıdır. EMG biofeedback ile küçük motor ünitelerin selektif aktivasyon kazanmasıyla progresif olarak büyük motor ünitelerde (sinerjilerde) inhibisyon elde edilebilir ${ }^{19}$.

Çalışmamızda, omuz eklemindeki sinerjileri azaltmak veya engellemek amaciyla üst trapezius kasina uygulanan EMG biofeedback eğitimi ile deltoideus kasında spesifik kontraksiyonların açığa çıktığını gözlemledik. Deltoideus kasındaki tonus artışı ile birlikte MFT'nin alt skorları olan FL ve LE puanlarında anlamlı bir artış olması gözlemimizi desteklemektedir. Selektif kontraksiyonlar, izole eklem hareketlerinin açığa çıkması ve dolayısıyla fonksiyonel iyileşmenin gerçekleşmesi açısından önem taşımaktadır. Bununla birlikte üst ekstremitede yer alan sinerjilerin inhibisyonu için EMG biofeedback eğitiminin, tüm sinerjist kaslara uygulanması gerektiğini düşünmekteyiz. Çalışmamızda fonksiyonel iyileşmenin tespiti için Brunnstrom evrelemesine göre değerlendirme yapılmamış olması çalışmanın kısıtlılı̆̆ı olarak değerlendirilebilir.

İnme rehabilitasyonunda, konvansiyonel tedaviye ek veya bağımsız olarak uygulanan EMG biofeedback eğitimi, hemiplejide nörolojik ve fonksiyonel iyileşmeyi arttırmaktadır. Bununla birlikte EMG biofeedback'in inme rehabilitasyonunda kullanımı açısından cevabı bulunması gereken birtakım sorular vardır. Bunlar; inmeyi takiben hangi zaman aralıklarında daha çok verimli olacağı, rehabilitasyonda kullanılan diğer yöntemlere göre üstünlüğü ve uygulayıcının tedavideki rolü'dür. Bu ve bunun gibi soruların cevaplanabilmesi için daha fazla klinik çalışma yapılması gerektiğini düşünmekteyiz. Bu çalışmada, hemiplejik hastaların üst trapezius kasına uygulanan EMG biofeedback eğitiminin; kas tonusu ve fonksiyonel iyileşme üzerinde etkili olduğu görülmüştür. Kolay uygulama imkanı ve inme rehabilitasyonunda tamamlayıc1 tedavi sunması açısından EMG biofeedback'in klinikteki kullanımı artırılmalıdır.

\section{KAYNAKLAR}

1. Otman S, Karaduman A, Livanelioğlu A. Hemipleji Rehabilitasyonunda Nörofizyolojik Yaklaşımlar, Ankara, H. Ü. Sağlık Bilimleri Fakültesi Fizyoterapi ve Rehabilitasyon Bölümü Yayınları, 2010.

2. Cramer SC, Nelles G, Benson RR, Kaplan JD, Parker RA, Kwong KK. A functional MRI study of subjects recovered from hemiparetic stroke. Stroke. 1997;28:2518-27.

3. Adıgüzel H. Omuz ağrisı ve üst ekstremite spastisitesi olan hemiplejik hastalarda üst ekstremite fonksiyonelliğinin yürüyüşe olan etkisi (Yüksek lisans tezi). İzmir, Dokuz Eylül Üniversitesi, 2013

4. Kocabaş H. Hemiplejik hastalarda ağrllı omuz (Uzmanlık tezi). Konya, Selçuk Üniversitesi, 2013.

5. Keenan MA. Management of the spastic upper extremity in the neurologically impaired adult. Clin 
Orthop Relat Res. 1988;233:116-25.

6. Karaduman A, Yıldırım AS, Yılmaz ÖT. Bobath Kavramı Nörolojik Rehabilitasyonda Teori ve Klinik Uygulama. Ankara, Pelikan Yayıncllık, 2012.

7. Anand DP, Philippe V, Frederike MJ, Sandra S, Garth RJ, Michael PB. Are we underestimating the clinical efficacy of botulinum toxin (type A)? quantifying changes in spasticity, strength and upper limb function after injections of Botox to the elbow flexors in a unilateral stroke population. Clin Rehabil. 2002;16:654

8. Tate JJ, Milner CE. Real-time kinematic, temporospatial, and kinetic biofeedback during gait retraining in patients: a systematic review. Phys Ther. 2010;90:1123-34.

9. Giggins O, Persson U, Caulfeld B. Biofeedback in rehabilitation. J Neuroeng Rehabil. 2013;10:60.

10. Nakamura R, Moriyama S. Manual Function Test (MFT) and Functional Occupational Therapy for Stroke Patients. Rehabilitation Manual. 2000;8:1-41.

11. Frönlich-Zwahlen AK, Casertelli NK, Item-Glathorn JF, Mattiuletti NA. Validity of resting myotonometric assessment of lower extremity muscles in chronic stroke patients with limited hypertonia: a preliminary study. J Electromyogr Kinesiol. 2014;24:762-9.

12. Doğan-Aslan M, Nakipoğlu-Yüzer GF, Doğan A, Karabay I, Özgirgin N. The effect of electromyographic biofeedback treatment in improving upper extremity functioning of patients with hemiplegic stroke. J Stroke Cerebrovasc Dis. 2012;21:187-92
13. Cordo P, Wolf S, Lou JS, Bogey R, Stevenson M, Hayes $\mathrm{J}$ et al. Treatment of severe hand impairment following stroke by combining assisted movement, muscle vibration, and biofeedback. J Neurol Phys Ther. 2013;37:194-203.

14. Rayegani SM, Raeissadat SA, Sedighipour L, Rezazadeh IM, Bahrami MH, Eliaspour D et al. Effect of neurofeedback and electromyographicbiofeedback therapy on improving hand function in stroke patients. Top Stroke Rehabil. 2014;21:137-51.

15. Lourenção MI, Battistella LR, de Brito CM, Tsukimoto GR, Miyazaki MH. Effect of biofeedback accompanying occupational therapy and functional electrical stimulation in hemiplegic patients. Int J Rehabil Res. 2008;31:33-41.

16. Chen HX, Wang W, Xiao HQ, Wang H, Ding XD. Ultrasound-guided botulinum toxin injections and EMG biofeedback therapy the lower limb muscle spasm after cerebral infarction. Eur Rev Med Pharmacol Sci. 2015;19:1696-9.

17. McCrea HP, Eng JJ, Hodgson AJ. Saturated muscle activation contributes to compensatory reaching strategies following stroke. J Neurophysiol. 2005;94:2999-3008.

18. Trombly CA. Deficits of reaching in subjects with left hemiparesis: a pilot study. Am J Occup Ther. 1992;46:887-97.

19. Glanz M, Klawansky S, Chalmers T. Biofeedback therapy in stroke rehabilitation: a review. J R Soc Med. 1997;90:33-9. 